\title{
TIERRA DE VESPUCIO \\ CONSIDERACIONES SOBRE UNA CURIOSA REPRESENTACIÓN DEL ESTRECHO DE MAGALLANES EN LA TABVLA MODERNA ALTERIVS HEMISPHAERII, UN MAPA RECIEN CONOCIDO DEL SIGLO XVI
}

MATEO MARTINIC B. ${ }^{\mathrm{a}}$

\section{RESUMEN}

Hace algunos años se encontró un mapa manuscrito de principios de la tercera década del siglo XVI y que luego de ser comprobada su autenticidad fue presentado al ambiente académico como la primera representación del hemisferio occidental del mundo luego de su conocimiento geográfico tras el memorable periplo exploratorio y descubridor de Fernando de Magallanes entre 1519 y 1522 . En el artículo se hacen consideraciones acerca de la representación que la pieza contiene sobre la parte meridional del Nuevo Mundo (estrecho de Magallanes) y se da cuenta de las diferencias constatadables entre la misma y otros mapas conocidos para la época, así como se destacan novedades toponímicas, entre ellas el de Tierra de Vespucio para una parte del sur del paso interoceánico descubierto, denominación que es discutida en cuanto a su presunto origen, con el añadido de una hipótesis explicativa diferente para la curiosa y efímera denominación.

Palabras clave: Cartografía histórica, Estrecho de Magallanes, Patagonia, Tierra del Fuego.

\section{LAND OF VESPUCCI. CONSIDERING A CURIOUS REPRESENTATION OF THE STRAIT OF MAGELLAN IN THE TABVLA MODERNA ALTERIVS HEMISPHAERII, A RECENTLY DISCOVERED MAP FROM THE XVI CENTURY}

\begin{abstract}
Some years ago a manuscript map from the third decade of the 16th century was found. Once its authenticity had been verified, it was presented to the academic world as the first representation of the western hemisphere, after its geography had become known, following the memorable exploratory journey of Fernando de Magallanes between 1519 and 1522. In the article, observations are made about the representation of the southernmost part of the New World (Strait of Magellan) in the map; and the differences between this and other maps known by this time are evaluated. Moreover, some lesser-known toponyms are pointed out, among them the name Land

a Profesor Titular y Emérito, Universidad de Magallanes. Investigador Centro de Estudios del Hombre Austral, Instituto de la Patagonia. Universidad de Magallanes, Punta Arenas. mateo.martinic@umag.cl
\end{abstract}


of Vespucci for one part of the discovered southernmost interoceanic channel. The denomination and its presumed origin are discussed, adding a different explanatory hypothesis for this curious and ephemeral name.

Key words: Historical Cartography, Strait of Magellan, Patagonia, Tierra del Fuego.

\section{INTRODUCCION}

En 2009 en una compraventa hecha en Colombia entre privados fue materia de la misma un mapa manuscrito que parecía datar del siglo XVI según lo indica su título TAB. MODERNA ALTERIVS HEMISPHAERII. Se trata de un mapa de forma hexagonal dibujado con tinta sobre papel (tamaño 41 x $54 \mathrm{~cm}$ ), que muestra el océano Pacífico y parte de los territorios que lo enmarcan por el occidente y el oriente según el conocimiento geográfico que se poseía a comienzos del siglo XVI. La información sobre esta pieza no tardó en divulgarse en el ambiente académico interesado en la cartografía antigua pues incluye parte importante del Nuevo Mundo, aquella situada entre los grados 40 de latitud norte y 60 de latitud sur, con sectores litorales del sur y del occidente del mismo que fueron revelados para la geografía durante la segunda y la primera parte de la tercera décadas del siglo XVI y, asimismo territorios continentales e insulares de la parte oriental y sudoriental de Asia, comprendidas las islas de las especias (Molucas). En el dorso del documento, bajo el título De Molucis Insulis se incluye un resumen de la relación del viaje de Fernando de Magallanes escrita por Maximiliano Transylvanus en 1522. El interés despertado por la pieza pudo deberse al verse en ella la primera representación del océano Pacífico cuya inmensidad fue revelada para el conocimiento universal tras el retorno a Europa de los primeros sobrevivientes del memorable periplo del gran lusitano.

La investigación necesaria para establecer la autenticidad, antigüedad y autoría del documento fue realizada por Frederik Muller, adquirente del mismo, calificado especialista holandés en cartografía antigua, quien dio a conocer su resultado en una comunicación presentada en mayo de 2011 en Sidney, en el transcurso de una conferencia de The Australian and New Zealand Map Society, $y$ posteriormente en forma de artículo bajo el título de Tabula Moderna Alterius Hemisphaerii.
The oldest surviving map of the Pacific?, en el número 71 de la revista The Globe, Journal of the Australian and New Zealand Map Society Inc., correspondiente al año 2012, al que remitimos al lector interesado para una información completa y detallada.

En síntesis, se trata de un mapa auténtico, construido antes de 1525 por el geógrafo Lorenz Fries, originario de la ciudad alsaciana de Colmar (que también era médico y escritor), con taller de su oficio en Estrasburgo. Su objeto era complementar y actualizar con la más reciente información disponible el conocimiento geográfico sobre el hemisferio occidental de la Tierra para los efectos de una reedición de la Geografía de Claudio Ptolomeo prevista para 1525. En consecuencia Fries incorporó todas las noticias aportadas por los cronistas Pedro Mártir de Anglería (1516) y el conquistador Hernán Cortés (1524) sobre México y otros territorios septentrionales de América y por Maximiliano Transilvanus (1522) acerca del viaje de Magallanes con sus descubrimientos en el sur del Nuevo Mundo, el cruce del océano Pacífico, las tierras en él avistadas y sus hallazgos en Asia desde las islas Filipinas hasta las Molucas. Es claro que en cada caso Fries pudo utilizar tanto la información escrita como la cartográfica correspondiente a las que le fue posible acceder. Además, de acuerdo con Muller, aquél debió consultar otros mapas de la época en lo tocante a las regiones meridionales del Nuevo Mundo, el Pacífico y el islario sudoriental de Asia, como pudo ser el caso del planisferio elaborado por Nuño García de Toreno y las piezas de otros cartógrafos que fueron utilizados en 1524 para sostener la tesis española sobre la ubicación de las islas Molucas (antimeridiano de Tordesillas) en la junta hispano-lusitana de Badajoz; asimismo, disponer del planisferio construido por Martín Waldseemüller y de otros mapas de geógrafos contemporáneos. Toda esa información pudo incorporarse en este mapa manuscrito, el primero conocido sobre el océano Pacífico. La pieza se confeccionó grabando el dibujo geográfico en una 


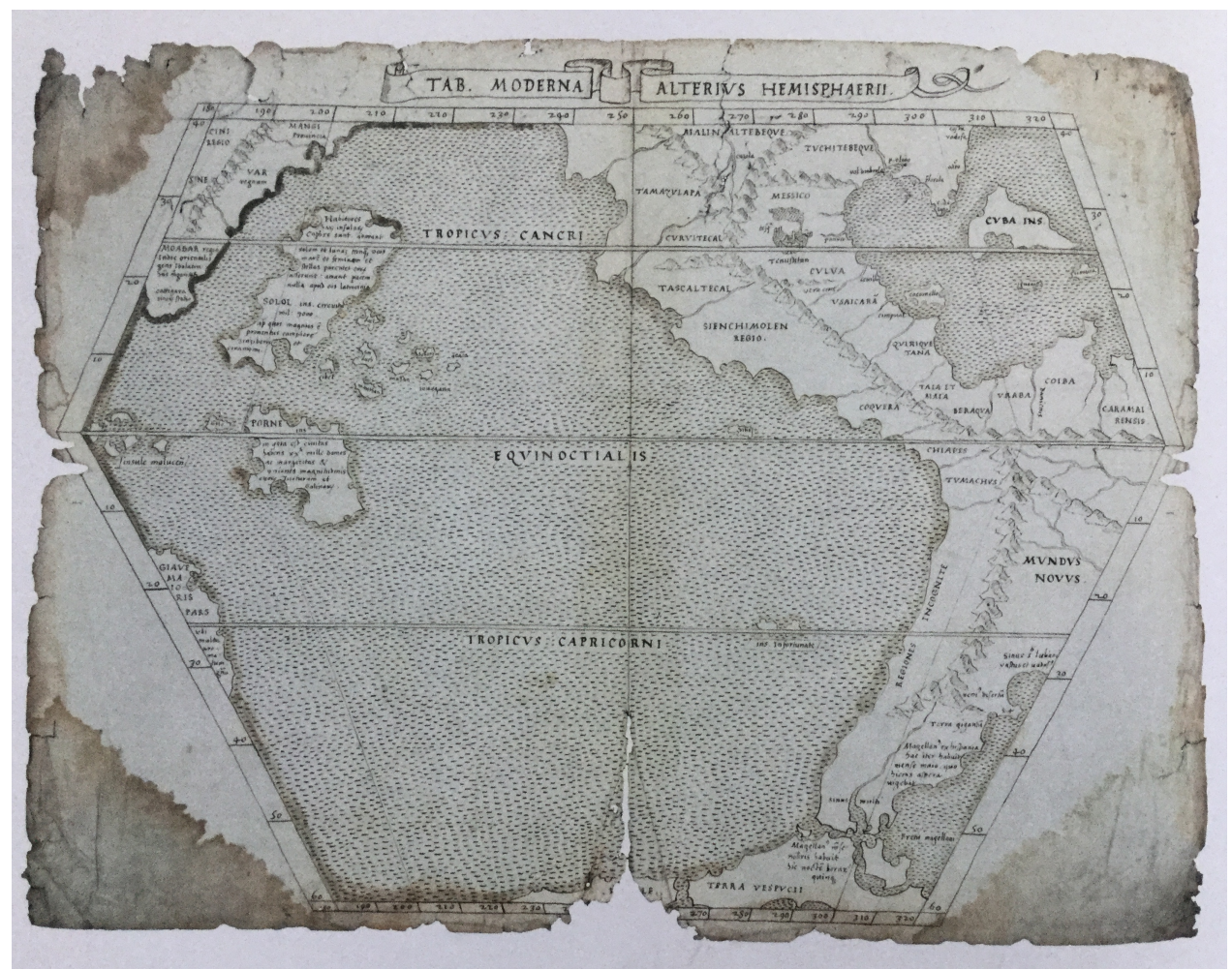

Fig. 1. Tabula Moderna Alterius Hemisphaerii. Lorenz Fries (1525). Anverso y reverso, facsimil reducido.

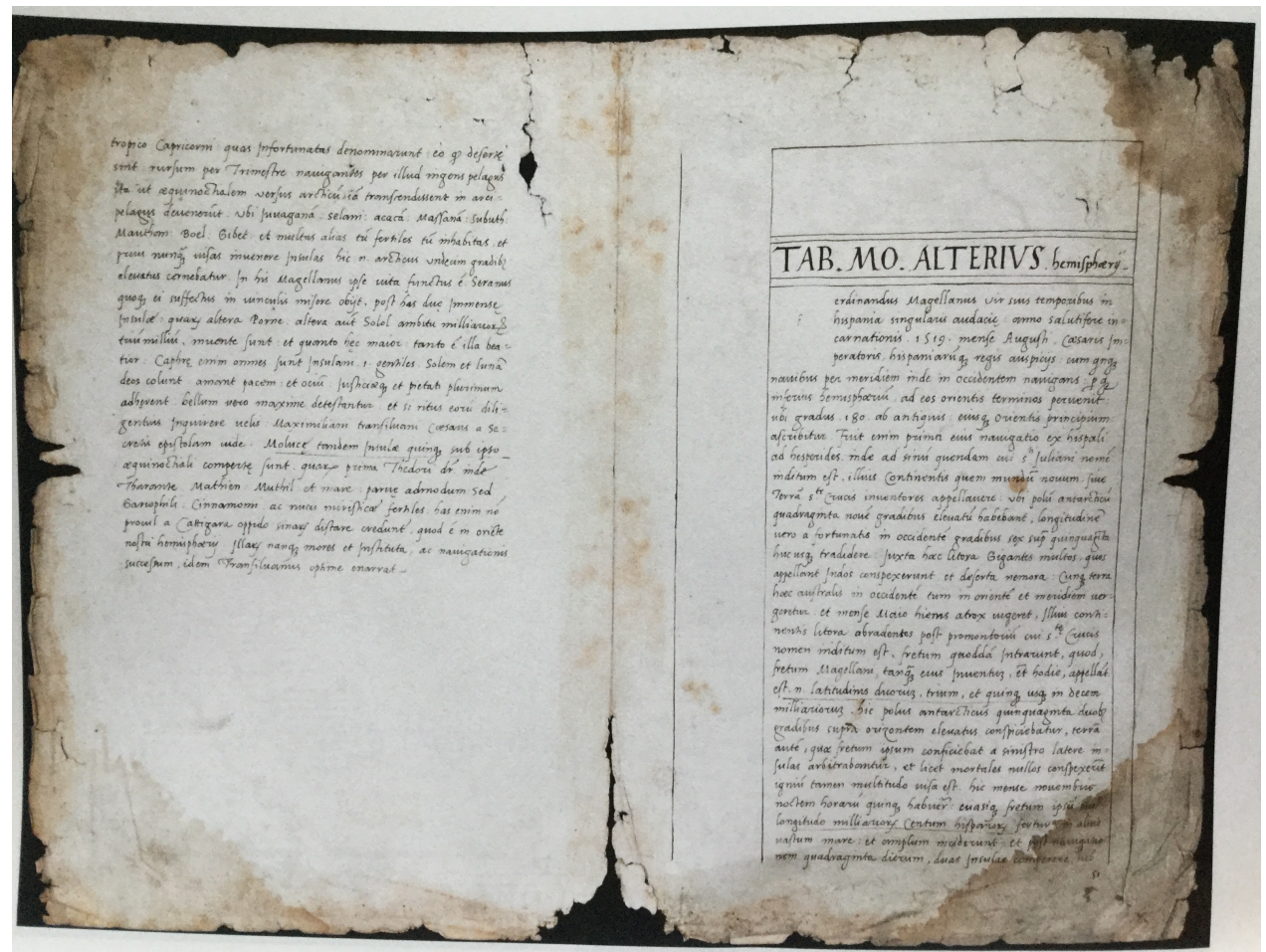




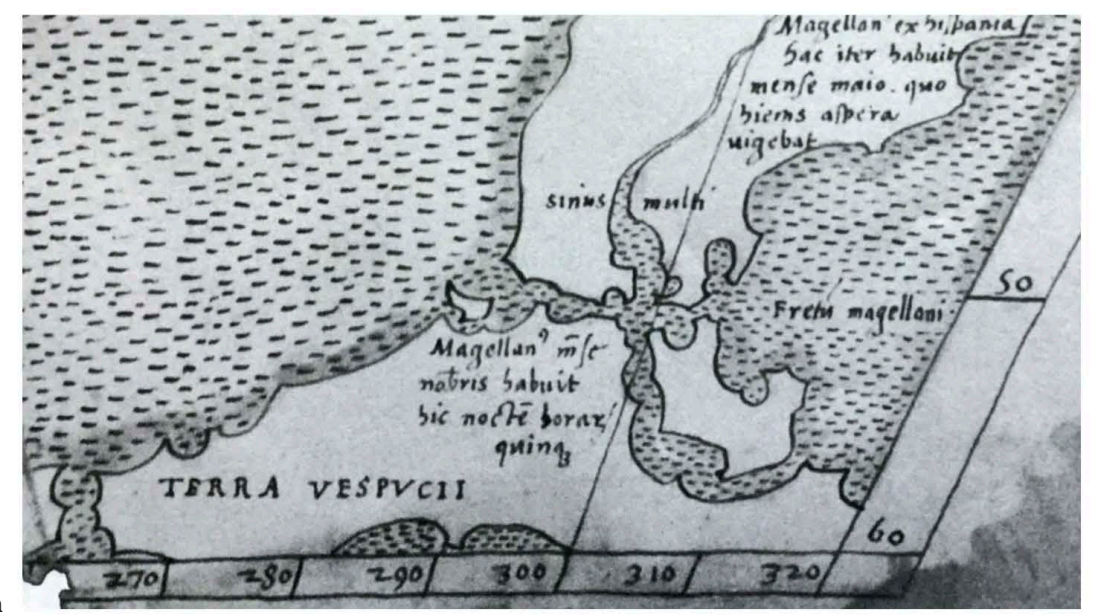

Fig. 2. Comparación de la representación del estrecho de Magallanes en mapas de la primera década después del retorno de la nao Victoria (1522-1533).

2a. Sector sudoriental de la Tabula Moderna; 2b. Padrón Real de Turín, atribuido a Nuño García de Toreno (ca. 1522-23); 2c. Carta Universal de Diego Ribero (Castiglioni) (1525); 2d.

Planisferio de Nuño García de Toreno (Salviati) (1525); 2 e. Planisferio de Juan Vespucio (1526); 2f. Mapamundi de Vesconte de Maggiolo (1527); 2g. Carta Universal de Diego Ribero (1529); 2h. Anónimo (Vaticano) (ca. 1530); 2i. Carta de América y Filipinas de Alonso de Chaves (1533).
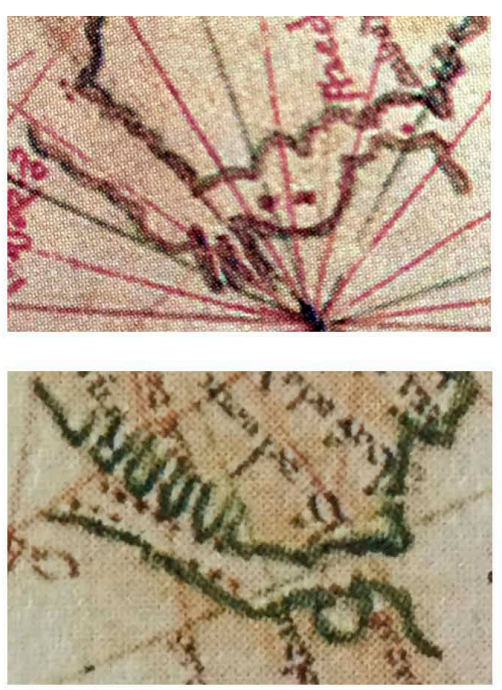

$2 d$
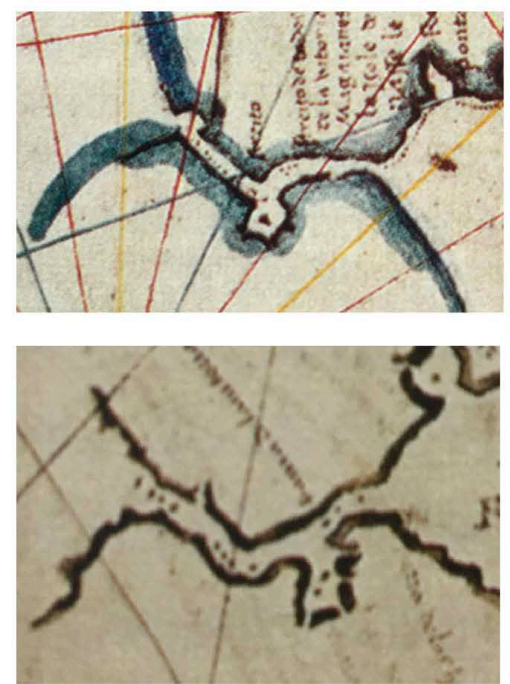

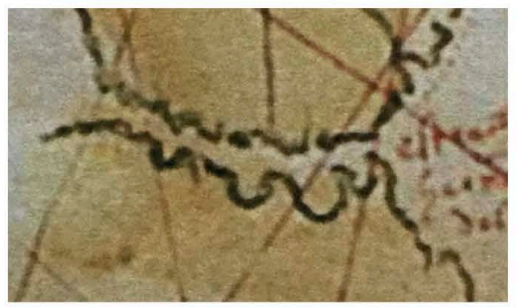

$2 c$

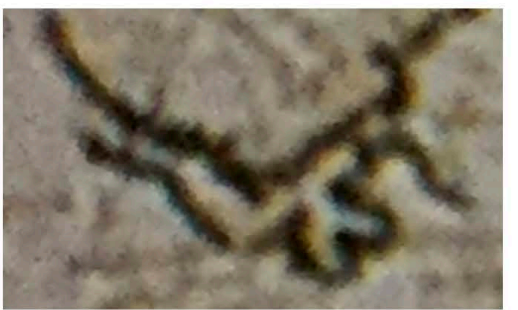

$2 \mathrm{~g}$

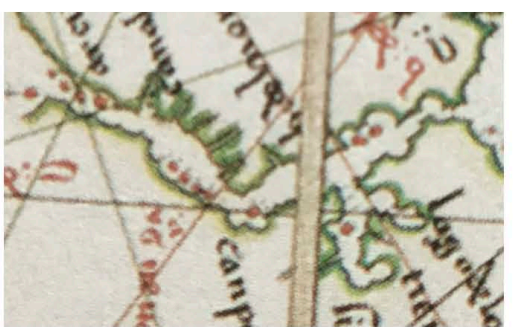

$2 e$

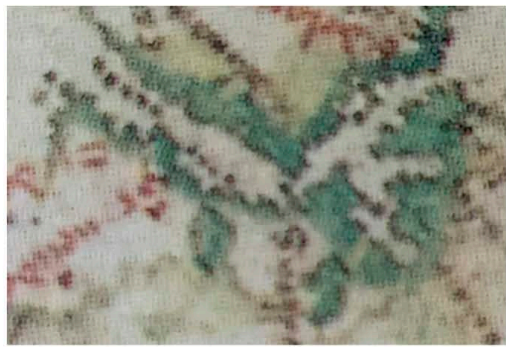

$2 \mathrm{i}$ 
tabla de madera para los fines de su impresión, aunque finalmente la reedición de la Geografía de Ptolomeo no incluyó la representación de que se trata. Esta interesantísima pieza se encuentra actualmente depositada en la Biblioteca Nacional de Australia, entidad que, así parece, es su propietaria (Fig. 1).

\section{CONSIDERACIONES ACERCA DE LAS FUENTES QUE INFORMARON LA REPRESENTACION DEL ESTRECHO DE MAGALLANES EN LA TABVLA MODERNA}

\section{a) Comparación con otras piezas contemporáneas (1523-1540)}

Al observarse la imagen cartográfica representada en el sector correspondiente a la parte austral de América por quien es conocedor de la cartografía más antigua disponible referida al estrecho de Magallanes, lo primero que llama la atención es la notoria desemejanza en la representación del gran canal que se advierte entre la Tabula Moderna y las piezas elaboradas durante la época con anterioridad y con inmediata posterioridad a la misma en lo concerniente a la representación de tierras y mares avistados por Magallanes, que han llegado hasta nuestros días. De alli que una primera consideración debe hacerse sobre este particular en procura de una explicación satisfactoria.

La vinculación que el propio autor, Fries, hace de su representación con la relación de Maximiliano Transilvanus ${ }^{1}, y$ tal vez de algún posible plano que la

1 Este personaje, flamenco de origen, era secretario personal del emperador Carlos V y además estaba casado con una sobrina de Cristóbal de Haro, empresario especiero que había sido uno de los aportantes financieros para la organización de la expedición de Magallanes. Estuvo así en ventajosa, casi excepcional posición para adquirir información sobre los pormenores del viaje a la llegada de los sobrevivientes del mismo a bordo de la nao Victoria en 1522. Se sabe que no solo fue testigo de oídas de la relación de hechos que Elcano y Pigafetta hicieron al monarca acerca de la gran expedición, sino que además él mismo procuró obtener de esos y otros sobrevivientes mayor información sobre el particular. Así informado, en octubre de 1522 Transylvanus escribió una carta a su padre Matthäus Lang, arzobispo de Salzburgo, participándole las novedades tenidas por sensacionales. El prelado valorando la información como el primer relato del viaje de Magallanes complementara, hace de la Tabvla la segunda pieza cartográfica conocida -además del Padrón Real de Turín de $1523^{2}$ - como portadora de las noticias geográficas referidas a la etapa fundamental del gran viaje, o sea, la correspondiente a la búsqueda, hallazgo y navegación del estrecho a través del Nuevo Mundo. Cabe así comparar las imágenes y anotaciones incluidas en ambas piezas.

Tocante a lo primero, la representación territorial contenida en el mapa de Fries difiere a simple vista del planisferio de Turín (y de otras piezas contemporáneas construidas por el mismo García de Toreno (Salviati), por Vesconte de Maggiolo, Diego Ribero, por el autor anónimo de 1530 y por Alonso de Chaves), en lo referido al rumbo en la declinación y al detalle del litoral oriental (atlántico), en que al revés de aquél que en el último aspecto lo muestra relativamente parejo con un par de entradas de costa notorias correspondientes a las actuales ría de San Julián y estuario del río Santa Cruz, la Tabula Moderna las presenta con inflexiones más pronunciadas. Pero donde la diferencia entre las piezas se hace bien notoria hasta divergir es en el trazado interior del Estrecho.

En efecto, en vez de presentarse el curso fretano siguiendo la forma de una gran "V" abierta con inflexión notoria en su parte inferior (meridional) a modo de penetración profunda característica de los primeros mapas mencionados, la Tabula de Fries lo demuestra exagerando las inflexiones, una inicial y profunda y otra aún más amplia interior sobre la parte norte que sirve de término a un río imaginario que procede del

alrededor del mundo la hizo publicar en Colonia en enero de 1523 bajo el título De Molucis Insulis. Tal fue la acogida brindada por el ambiente culto de Europa que se hizo necesaria una segunda edición en París (julio) y luego otras dos en Roma (noviembre de 1523 y febrero de 1524), lo que permite entender la rapidez de la difusión de la relación de Transylvanus antes de que concluyera 1524

2 Con esta denominación es comúnmente conocido en el ambiente académico especializado un planisferio o carta universal elaborado entre 1522 y 1523 al parecer por el cartógrafo español Nuño García de Toreno, cosmógrafo de la Casa de Contratación de Sevilla y basado en el padrón real allí conservado, pieza que se halla depositada en la Biblioteca Real de Turín. Este mapa es el primero conocido que recogió y representó el hallazgo geográfico del estrecho a través del Nuevo Mundo por Fernando de Magallanes y que lleva su nombre. 
septentrión; y, por la parte del sur, una tercera todavía más extensa, profunda y curvada hacia el este en la zona del meridión que divide en dos la tierra firme contigua (preanunciando lo que siglos después, a partir del XVIII, se conocería como mítico "canal de San Sebastián"). La comparación se extiende obligadamente hacia el sur para ver lo que ocurre con los trazados litorales oceánicos correspondientes. Así, en el Padrón Real y otros planisferios de la época estos son apenas insinuados al meridión del Estrecho dándose a entender de ese modo el desconocimiento que había sobre su continuidad, mientras que en el plano de Fries se prolongan por el sudeste, el sudoeste y el sur encerrando una triple porción territorial muy amplia en su parte meridional, una mayor directamente al sur del Estrecho y otra menor separada por un canal hacia el sudoeste que origina una isla menor hacia el noroeste. De esa manera la actual Tierra del Fuego es presentada dividida en tres partes insulares, una pequeña hacia el noreste entre el Estrecho y el Atlántico $y$ las otras dos mencionadas previamente. Este diseño es especialmente valorado por Muller que lo considera la primera representación de la más adelante archinombrada Terra Australis Incognita extendida hacia el sur y el oeste.

A la vista de ambas figuraciones cabe preguntarse por qué el dibujo de la Tabula Moderna difiere tan notoriamente de las otras representaciones contemporáneas que nos son conocidas y que estaban disponibles en la época. Reflexionando sobre ello se nos ocurre que Lorenz Fries pudo dibujar de memoria basándose en la relación de Transylvanus y en algunas noticias que, quizá, pudo conseguir de algún otro de los compañeros de Magallanes retornados y, por tanto, sin tener ante sus ojos otro esquicio, bosquejo o plano que le pudiera servir de modelo para su propia elaboración.

Esta conjetura se nos presenta como más posible cuando se lee la parte de la relación de Transylvanus referida a la tierra austral contigua al tramo occidental terminal del Estrecho, en que se expresa que los tripulantes de las naos de

3 Al hacer esta afirmación nos fundamos en el texto completo de la relación de Maximiliano Transylvanus comentado y transcrito entre otros documentos concernientes al viaje de Magallanes, por Xavier de Castro et.al. en su libro Le
Magallanes estimaron que aquella parte del ámbito avistado no era tierra firme sino islas por el ruido que hacía el oleaje del mar al batir las costas por ese lado, referencia repetida en el sumario del relato escrito en el dorso de la Tabula.

La conjetura acerca de una posible relación circunstancial con alguno de los sobrevivientes del viaje la derivamos de la frase... Hic polus antarcticus quinquaginta duobus gradibus supra orizontem elevatus conspiciebatur (Aqui la estrella polar austral ha sido observada elevada a $52^{\circ}$ sobre el horizonte) incluida en el resumen de la relación de Transylvanus escrito al dorso del mapa y que no se contiene en la carta-relación del antiguo secretario del emperador Carlos $\mathrm{V}^{3}$. Como se trata de un dato específico e interesante que el geógrafo desconocía, su mención escrita únicamente pudo fundarse en la información proporcionada por un testigo del hecho astronómico, esto es, uno de los antiguos tripulantes que participó como colaborador en alguna de las observaciones de la especie o bien supo de ellas por boca de tercero. Ergo, no es una exageración pensar que Fries amén de la lectura de la relación de Transylvanus pudo conocer y tratar a algún otro de los retornados en la Victoria.

Veamos desde luego la parte del resumen incluido en el dorso del mapa de Fries en lo que interesa al punto para los efectos de su debida consideración: La primera etapa de esta travesía navegatoria fue desde Sevilla a las Islas del Cabo Verde y desde alli a una bahía que fue nombrada de San Julián en el continente que sus descubridores llamaron el Nuevo Mundo o la Tierra de Santa Cruz, donde encontraron la Estrella Polar Austral a los 49 grados y donde ellos navegaron hasta los $56^{\circ}$ de longitud al oeste de las Islas Canarias. A lo largo de esa costa vieron muchos gigantes que ellos llamaron Indios y tierras desiertas. Esta tierra austral se extiende al oeste, al este y al sur y [ellos] soportaron un terrible invierno durante el mes de mayo y exploraron las costas del continente $y$ encontraron detrás de un promontorio al que nombraron Santa Cruz, un Estrecho que ellos llamaron "Estrecho de Magallanes" hasta el día

Voyage de Magellan (1519-1522). La relation d'Antonio Pigafetta \& autres témoignages (Editions Chandeigne, Paris 2007, tomo II La Letre de Maximilianus Transylvanus, pp. 883-918. 
de hoy.

Su ancho es dos, tres, cinco y aun diez millas. Aquí la Estrella Polar austral fue vista elevándose a 52 grados sobre el horizonte y tuvieron la impresión que la tierra ribereña del Estrecho en la parte izquierda [babor] consistía en islas y observaron una cantidad de fogatas por diferentes partes aunque no vieron persona viviente alguna. Tuvieron una noche que solo duraba cinco horas en el mes de noviembre. Habiendo navegado el Estrecho cuya longitud ellos estimaron en 100 leguas españolas, ellos accedieron a otro vasto gran mar4. El texto completo de la relación de Transylvanus a la que se hace referencia y aunque no es mucho más extenso en la parte que interesa (incluida entre las pp. 899 y 901 del libro de Castro citado), contiene alguna mayor información para comprender la geografía descubierta y recorrida, pero, cabe preguntarse, si ello fue suficiente para el trazado del mapa que se trata.

Y tornando al trazado geográfico de la Tabula Moderna, como afirma Muller, Fries conoció la Carta de Navegación de Castilla a los Malucos, el principal de los mapas elaborados sobre el viaje de Magallanes y que fue utilizado en las reuniones de Badajoz y Elvas de 1524 entre castellanos y lusitanos a fin de resolver las diferentes interpretaciones acerca de la ubicación del antimeridiano de Tordesillas (de lo que dependía la jurisdicción sobre las islas de las especias), carta cuya autoría se atribuye a Nuño García de Toreno, se nos hace muy difícil aceptar que la "imagen cartográfica del Estrecho" que el alsaciano nos ha dejado en su Tabula se correspondiera con la ofrecida en aquel desaparecido planisferio. Todo lo que se sabe de esta importante pieza autoriza a concluir, vista la misma autoría cartográfica, en la evidente semejanza de la correspondiente imagen con la conocida brindada por el Padrón Real de Turín y, por tanto, la diferencia notoria que se da en el trazado del Estrecho entre las contenidas en esas piezas y la imagen legada por Fries. Por ello, aceptando que el geógrafo alsaciano pudo conocer la carta famosa, todo cuanto el mismo pudo hacer al confeccionar la parte correspondiente de la Tabula fue recordar malamente la imagen que en aquella había podido observar. No habría sido así, entonces, más que uno de los tantos mapas construidos "de memoria", esto es sin modelo precedente a la vista, como debió ocurrir repetidamente en la época. No se ve en el trabajo de Lorenz Fries el cuidado y la prolijidad de trazo que se advierte en las piezas elaboradas por cartógrafos profesionales tales como García de Toreno, Diego Ribero y Alonso de Chaves entre otros de aquel tiempo lejano. Eso aparte del incomprensible error en el que incurrió Fries al situar en los $30^{\circ}$ la latitud de la bahía de San Julián, esto es una diferencia de dieciocho grados, lo que nos mueve a dudar de la calidad del médico alsaciano como cartógrafo, tal como lo hiciera hace ya tiempo un experto tan afamado como fuera $\mathrm{N}$. A. Nordenskiöld según Frederik Muller.

Es más, en una comparación extendida a las principales piezas (planisferios) que se conocen para la época, en especial a las correspondientes a la década que siguió al retorno de la nao Victoria, incluido en burdo bosquejo de Thorne, se puede apreciar que todas ellas se ciñen a una suerte de patrón en el diseño geográfico (fisiográfico) que difiere de lo que muestra la Tabvla Moderna (Fig. 2).

Abundando, conviene recordar las circunstancias o accidentes geográficos definitorios del trazado del gran canal interoceánico, esto es, de oriente a occidente: el cabo Vírgenes, el saco oriental, las angosturas, el espacio intermedio entre ambas y el ensanche a continuación de la segunda de ellas; la bifurcación del paso marítimo y la noción de una penetración profunda hacia el sureste, el laberinto marino sugerido por tantas bocas o entradas de canales que se abren al norte y al sur de la gran vía de navegación, la diferente amplitud del mismo según sectores y la longitud estimada para el Estrecho, en fin, como principales hechos caracterizadores de la fisiografía fretana. La Tabula efectivamente recoge esas diferentes expresiones si bien exagerándolas notoriamente en los casos de complejo laberíntico de la mitad occidental del Estrecho y el de la penetración sudoriental, tanto en este caso como para dividir la tierra austral del gran canal y generar de ese modo hacia el noroeste una isla inexistente. Esta explicación se nos presenta más razonable cuando se lee la parte de la relación de Transylvanus referidas a la tierra austral contigua 
al tramo occidental terminal del Estrecho en la que se recuerda una gran masa compacta parecía ser más bien un conjunto de islas impresionados como pudieron estar por el estruendoso batir del oleaje que oyeron al navegar aquel tramo terminal. Y en ello anduvieron acertados con lo que posteriores exploraciones y descubrimientos revelarían respecto a la forma, dimensiones y demás de la parte meridional del continente americano. La sensación auditiva pudo más que la visual con el imaginario correspondiente de esa gente.

b) Consideraciones acerca de la toponimia de la Tabula Moderna

En lo tocante a la toponimia fretana la diferencia entre la pieza elaborada por Fries y las demás que se conocen es total pues la Tabula solo comparte unos pocos nombres con el planisferio de Turín y otros mapas de la época, siendo mayores las omisiones que hace de otros compartidos comúnmente por ellos (i.a. cabo de las Vírgenes, Tierra de los Humos, Tierra de los Fuegos, lago del Estrecho, etc.). Incluye en cambio dos menciones descriptivas y un topónimo novedoso. Las primeras, Sinus multi (Muchas entradas) y Magellanus mense novembris habuit hic noctem horarum quinque (En noviembre Magallanes encontró aquí noches de cinco horas), son referencias derivadas de las sensaciones y comprensiones de los tripulantes de la armada de Molucas acerca de la complejidad geográfica laberíntica de la vasta sección occidental del Estrecho y sobre la brevedad del tiempo nocturno durante la primavera austral, impresiones que la gente pudo conservar y relatar con posterioridad, lo que afirma nuestra conjetura respecto de la posibilidad de algún contacto personal de Fries con uno o más de los retornados de la Victoria.

El topónimo novedoso es Terra Vespucci (Tierra de Vespucio) con el que se designa a la mayor de las porciones insulares trazadas en la parte austral del estrecho de Magallanes. Nombre que amén de novedoso encontramos sorprendente y merecido. Cabe abundar sobre el punto.

La denominación de primera llama la atención por cuanto en la toponimia original geográfico del espacio revelado por Magallanes con su memorable travesía no incluye alguna denominación motivada en personas, excepción hecha de los nombres Estrecho Patagónico y Región Patagónica inspirados en el los aborígenes conocidos en San Julián durante el invierno de 1520 y estampados por Pigafetta en su mapa de 1525. En este aspecto Fries en la Tabula Moderna hace una doble excepción pues además del topónimo concerniente a Vespucio incluye la denominación Fretu magellani (Estrecho de Magallanes) para el gran canal interoceánico descubierto y navegado durante la travesía famosa, con lo que se sitúa en la vanguardia de los que reconociendo el mérito del navegante lusitano no se demoraron en consagrarlo cartográficamente para memoria de la posteridad. Por eso, tornando al primer topónimo, la referencia a Amerigo Vespucci aparece en verdad como algo excepcional cuya motivación debió tener una gran fuerza inspiradora.

Frederik Muller opina que Ese reconocimiento era típico para el grupo de académicos de Saint-Die, como también para el grupo de Estrasburgo, en una consideración que los vincula así a ambos, el primero de comienzos del siglo XVI donde figuraban el humanista Matthias Ringmann y Martín Waldseemüller (el cartógrafo que había asignado el nombre de Vespucio en su tan afamado planisferio de 1507 para identificar una parte meridional del Nuevo Mundo), y el segundo de la década siguiente donde participaba Lorenz Fries. Pero ¿puede sostenerse que tal reconocimiento, de haberse dado, se mantenía todavía vigente pasado 1520 ? Nos surgen dudas en este sentido pues desde la actividad del cenáculo de Saint-Die -cuyo momento histórico de fama fue la edición de la Geografía de Claudio Ptolomeo acompañada con el planisferio elaborado por Waldseemüllerhabían corrido casi dos décadas para cuando Fries se ocupaba de una nueva reedición actualizada de la célebre obra del geógrafo de la antigüedad, y una al menos, desde la muerte de Vespucio (1512); ello por una parte y por otra que la fama del florentino había sufrido para entonces los primeros avatares por las imputaciones que algunos geógrafos habían hecho y hacían en cuanto que Vespucio se había apropiado de (o se le había atribuido) un merecimiento que no le correspondía, circunstancia que lo presentaba ante el mundo como un mero advenedizo en el 
conocimiento de la geografía del Nuevo Mundo ${ }^{5}$. Así, tornamos a preguntarnos acerca de qué tanta fama del mismo podía persistir en el ambiente de la especialidad cartográfica hacia comienzos de la tercera década del siglo XVI como para que se honrara a Amerigo Vespucci con tan singular reconocimiento toponímico como el realizado por Lorenz Fries en su versión actualizada de la Tabula Moderna.

Según los datos entregados por Muller, Fries había nacido en Colmar, Alsacia, hacia 14851490, lo que significa, en el caso de la fecha más antigua probable, que para la época de la edición de la Geografía de Ptolomeo y del planisferio de Waldseemüller era un hombre todavía joven preocupado posiblemente de sus estudios de medicina $y$, quizá, sin nociones del cenáculo de Saint-Dié y sus trabajos, incluida la supuesta influencia de Vespucio sobre ellos, lo que lleva a suponer que el alsaciano se enteró sobre el asunto años después. Por otra parte, para comienzos de la tercera década del siglo XVI no solo había fallecido Vespucio, sino casi todos los integrantes del famoso cenáculo académico, con lo que cabe preguntarse acerca de qué manera pudo Fries informarse sobre la materia hasta acabar asignando a Vespucio, según Muller, un topónimo en su Tabula Moderna de 1525. Esta es una incógnita particular que habría que desvelar.

Por nuestra parte proponemos una segunda hipótesis explicativa y que derivamos de la interesante vinculación que pudo darse en la génesis histórica de la gran empresa magallánica (el acceso a las tierras de la especiería navegando desde el oriente a través de un paso que debía hallarse en la masa continental del Nuevo Mundo), entre los conocimientos que pudo adquirir y las ideas que consiguió desarrollar Amerigo Vespucci acerca de la navegación en la zona sudoriental del continente americano, y las que a su tiempo obtuvo e igualmente se planteó Fernando de Magallanes para llevar adelante su iniciativa, aspecto este de nuestra reciente preocupación académica $e$ historiográfica 6 .

Se trata de la motivación que pudo brindar

5 Esta circunstancia explicaría la omisión del cuestionado topónimo por el propio Waldseemüller en su reedición de 1516.

6 Cfr. Una travesía memorable. Hallazgo y navegación del el reconocimiento profundo de Fernando de Magallanes y sus compañeros por la inspiración que diera el florentino a la empresa descubridora de la Armada de Molucas en lo referido al rumbo para encontrar y navegar el paso por el Nuevo Mundo entre los mares del Norte y del Sur, hecho felizmente realizado entre el 21 de octubre y el 28 de noviembre de 1520 .

En efecto, al cabo de larga reflexión sobre la base de los antecedentes disponibles sobre aquel gran viaje hemos adquirido el convencimiento de que tal pudo ser pues en las sugerencias $e$ intuiciones que le brindara a Vespucio su experiencia navegatoria de 1502 por la costa oriental sudamericana hasta aproximadamente los $50^{\circ}$ sur y las reflexiones que pudo añadir con posterioridad, y que, tomadas en conjunto, pudieron conformar un acervo informativo que el florentino traspasó a su sobrino Juan y a su apoderado Andrés de San Martín antes de su fallecimiento. Este último a su vez hubo de participar a Magallanes tan valiosa información cuando ambos se conocieron en la década de 1510. En ello, pues, encontramos el fundamento que explica la convicción que tuvo Magallanes acerca del curso que debía seguir su navegación exploratoria y la tenaz insistencia en mantener el rumbo de navegación que la historia conoce, determinación finalmente gratificada con el hallazgo del 21 de octubre de 1520 y la posterior navegación exploratoria del paso interoceánico que después llevaría su nombre. Con Andrés de San Martín a bordo en calidad de piloto y cosmógrafo, debieron ser dos los que repetidas veces pudieron recordar a Vespucio tras la partida de San Julián hacia el sur en agosto de 1520. Si asî pudo ser, reiteramos ¿cómo no pensar que cuando en el momento de comprobación del hallazgo determinante, hallándose las naos en el acceso a la primera angostura del Estrecho, se recibió de boca de los capitanes Serrano y Mezquita la información de que las aguas en las que se encontraban podían corresponder efectivamente a un paso de mar, no viniera a la mente de Magallanes y San Martín el recuerdo agradecido hacia Amerigo Vespucci y su acertada inspiración de la ruta? Si tal pudo suceder,

estrecho de Magallanes. 21 de octubre-28 de noviembre de 1520. Edición de Aguas Magallanes S.A. Punta Arenas, 2016. 
inferir que de tal sentimiento de gratitud derivara la ulterior utilización del nombre del florentino para honrar su memoria siquiera para una parte de la gran tierra del sur del Estrecho, no nos parece una demasía, sino la prueba tangible de un homenaje de reconocimiento merecido por demás por Américo Vespucio. Ese recuerdo bien pudo trascender a terceros entre los compañeros del viaje famoso y ser finalmente recogido por el cartógrafo Lorenz Fries.

En la discrepancia acerca de la razón del curioso y efímero topónimo asignado a una mayor parte de la tierra del sur del estrecho de Magallanes, juzgue el lector aceptando la interpretación que le parezca más sustentable: si la de que el mismo estuvo motivado en el tributo de un supuesto tardío admirador del navegante florentino, o bien si la denominación respondió al eco de un profundo reconocimiento de Magallanes y compañeros hacia la figura de Amerigo Vespucci que fuera el inspirador del rumbo en la etapa crucial de su memorable travesía histórica.

En conclusión, valoramos especialmente el mapa Tabula Moderna Alterius Hemisphaerii en lo que a la región del estrecho de Magallanes se refiere tanto por la excepcional asignación toponímica considerada, cuanto por el hecho de consignar por vez primera la denominación del Estrecho con el nombre de su descubridor.

\section{AGRADECIMIENTOS}

Dejamos constancia de nuestro agradecimiento para con la bibliotecóloga señora Ximena Silva cuya diligencia hizo posible ubicar el artículo que ha servido de fundamento a esta comunicación y a la Dra. Flavia Morello por su gentil disponibilidad para adquirir la revista The Globe donde aquél fuera publicado. Asimismo al editor de la misma por autorizar la reproducción de la imagen de la Tabula Moderna Alterius Haemispherii cuyos derechos posee. Finalmente, al arquitecto e investigador Samuel García O. por su colaboración en la elaboración de las figuras que ilustran el artículo.

\section{BIBLIOGRAFÍA}

GARCIA REDONDO, J. M. (2014). La percepción histórica del inmenso azul: modelos de representación en la cartografía del océano Pacífico. En El Mar del Sur en la historia. Ciencia, expansión, representación y poder en el Pacífico. Rafael Sagredo Baeza, Rodrigo Moreno Jeria (Coordinadores). Santiago de Chile: UAU Universidad Adolfo Ibañez. DIBAM Dirección de Bibliotecas, Archivos y Museos y Centro de Investigaciones Barros Arana.

KLEIN, M. (2016). Cartography of Southern South America. En Atlas of Cape Horn. The Cartography of Southern South America 1500-1725. Pieter Kroon, General Editor. THOTH Publishers Bussum-Foundation 400 Years Cape Horn.

MARTINIC, M. (1997) Cartografía Magallánica 1523-1945. Ediciones Universidad de Magallanes. Punta Arenas.

MARTINIC, M. (2016) Una travesía memorable. Hallazgo y navegación del estrecho de Magallanes. 21 de octubre- 28 de noviembre 1520. Punta Arenas: Edición de Aguas Magallanes S.A.

MULLER, F. (2012). TABVLA MODERNA Alterius Hemisphaerii: The oldest surviving map of the Pacific? The Globe, Journal of the Australian and New Zealand Map Society Inc. Number 71. Sidney. 